\title{
Synthesis and Stability of a Nanoparticle-Infiltrated Solid Oxide Fuel Cell Electrode
}

\author{
Tal Z. Sholklapper ${ }^{1+\#}$, Velimir Radmilovic ${ }^{\circledR}$, Craig P. Jacobson ${ }^{+}$, Steven J. Visco ${ }^{+}$, \\ and Lutgard C. De Jonghe ${ }^{+\#}$ \\ ${ }^{+}$Materials Science Division, Lawrence Berkeley National Laboratory, \\ Berkeley, CA 94720, USA, \\ ${ }^{\circledR}$ National Center for Electron Microscopy, Lawrence Berkeley National Laboratory, \\ Berkeley, CA 94720, USA, \\ and \\ ${ }^{\#}$ Department of Materials Science and Engineering \\ University of California at Berkeley \\ Berkeley, CA 94720, USA.
}

\section{Abstract}

Nanoparticulate catalysts infiltrated into SOFC (Solid Oxide Fuel Cell) electrodes can significantly enhance the cell performance, but the stability of these electrodes has been an open issue. An infiltration procedure is reported that leads to a stable scandia-stabilized zirconia (SSZ) cathode electrode performance.

An SSZ cathode, infiltrated with 50-150nm lanthanum -strontium manganate (LSM) electrocatalyst particles, is shown to be voltage-stable for over 500 hours of operation at $650^{\circ} \mathrm{C}$, at a controlled current density of $150 \mathrm{~mA} / \mathrm{cm}^{2}$. This demonstrates the potential viability of nanoparticulate-infiltrated electrodes for commercial SOFCs, and illustrates the functional stability of nanoparticulate catalysts in the demanding environment of SOFC electrodes.

\section{Introduction}

Nanoparticulate catalysts may be infiltrated into already formed SOFC electrodes to enhance electrode performance ${ }^{1-4}$, and new electrode designs have been devised utilizing continuous nanoparticulate networks or connected nanoparticle rafts $^{4-9}$. In these electrode designs, the nanoparticulates not only serve as reaction sites, but also provide an electron pathway from the current collector to the individual reaction sites. Hence, persistent connectivity of the nanoparticulate networks and limited coarsening are essential to stable electrode function. Although a number of papers have been published on nanoparticle-infiltrated electrodes, little mention has been made of the

1 Corresponding author e-mail: tsholk@berkeley.edu 
extended stability of such structures. The difficulty is that SOFC electrodes operate under demanding operating conditions: elevated temperatures $\left(600^{\circ} \mathrm{C}-1000^{\circ} \mathrm{C}\right)$, thermal cycling, high local current densities, and high local potential gradients. These conditions can be antagonistic to the stability of nanoparticulate networks.

Nanoparticle-infiltrated porous $\mathrm{ZrO}_{2}$-based electrodes were prepared in a single processing step $^{5}$; the cells showed an adequate initial performance at $650^{\circ} \mathrm{C}$, but their extended stability was not examined. Further evaluation of similar nanoparticulate-LSM infiltrated, porous SSZ (scandiastabilized zirconia) electrodes proved, for the first time, their functional stability for over 500 hours of operation at $650^{\circ} \mathrm{C}$. The microstructures produced by the infiltration method are examined, and related these to essential requirements for stability of nanoparticle-infiltrated SOFC electrodes. Additionally, a focused ion beam (FIB) method was used for producing scanning electron microscope (SEM) crosssections and lift-out thin sections for transmission electron microscopy (TEM) with minimal artifacts.

\section{Methods}

$\mathrm{NiO}$ (J. T. Baker) and SSZ [i.e. (Sc2O3)0.1(ZrO2)0.9; from Daiichi Kigenso Kagakukokyo] in a weight ratio of 1:1 were attritor-milled in isopropanol, using zirconia balls as the milling medium. Dried mixtures were uniaxially pressed and pre-fired at $1100{ }^{\circ} \mathrm{C}$ for $1 \mathrm{~h}$. SSZ electrolytes were formed on the NiO-SSZ anode supports by colloidal deposition ${ }^{10}$, and were co-sintered at $1350{ }^{\circ} \mathrm{C}$ for $4 \mathrm{~h}$. A suspension of SSZ and graphite was then colloidally deposited onto the SSZ electrolyte to prepare a thin layer consisting of SSZ and graphite, with an area of $1 \mathrm{~cm}$. The resulting trilayer structure was sintered at $1250{ }^{\circ} \mathrm{C}$ for $4 \mathrm{~h}$, during which graphite was burned out, leaving a porous, well-formed SSZ network. A solution of LSM (La0.85Sr0.15MnO3) precursor was prepared by combing 3.144g $\mathrm{La}\left(\mathrm{NO}_{3}\right)_{2} \cdot 6 \mathrm{H}_{2} \mathrm{O}$ (Alfa Aesar), 2.452g $\mathrm{Mn}\left(\mathrm{NO}_{3}\right)_{2} \cdot \mathrm{XH}_{2} \mathrm{O}$ (X=0.6-0.4, 5 assumed; Aldrich), 0.271g $\mathrm{Sr}\left(\mathrm{NO}_{3}\right)_{2}$ (Alfa Aesar), 0.3g of a commercial polymeric dispersant (Triton-X100, Union Carbide 
Chemicals and Plastics Co., Inc.) and $10 \mathrm{~mL} \mathrm{H}_{2} \mathrm{O}$, and subsequently heating to $100^{\circ} \mathrm{C}$ to produce a high concentration suspension. The increasingly viscous suspension was then infiltrated into the porous SSZ network using a vacuum impregnation apparatus (Epovac; Struers), and the precursors were then converted by heating at $900{ }^{\circ} \mathrm{C}$ for $0.5 \mathrm{~h}$. Platinum-paste current collectors were placed on the electrodes, and then fired on, again at $900{ }^{\circ} \mathrm{C}$ for 0.5 hour.

The resulting membranes were either held at $650{ }^{\circ} \mathrm{C}$ or electrochemically characterized, by sealing onto an alumina tube using Aremco-552 cement, and current-voltage characteristics were obtained, with $97 \% \mathrm{H}_{2}+3 \% \mathrm{H}_{2} \mathrm{O}$ as the fuel and air as the oxidant. The cell DC current-voltage (I-V) performance was determined at $650{ }^{\circ} \mathrm{C}$ with a potentiostat-galvanostat (Princeton Applied Research Model 371). After electrochemical characterization, the cells were then fractured and further crosssectioned using a dual focused ion and electron beam (FIB/SEM; FEI Strata 235 M) system. SEM images were taken after cross-sectioning with the FIB. Sections were also prepared for transmission electron microscope analysis (TEM; JEOL, JEM-200CX) by a lift-out technique using the above FIB/SEM system ${ }^{11}$.

\section{Results and Discussion}

The microstructure that the infiltration method produces ${ }^{5}$, and its relation to the stability of the cathode is first characterized by scanning electron microscope. From the FIB cross-sectional SEM image, Figure 1, it is evident that the infiltration method produces a well-connected network and rafts of nanoparticulate LSM, confined nearly exclusively to the pore walls of the SSZ cathode backbone, providing a sufficient percolation path for electrons to the majority of the oxygen reduction reaction (ORR) sites. 
These reaction sites are either near the SSZ/LSM pore triple junctions (TPBs) or on the surface of the dense LSM rafts. Since the LSM rafts produced by our method are generally just one nanoparticle thick, i.e. 50-150 nm (see inset in Fig. 1), oxygen ion conduction directly through the dense raft can contribute significantly to the overall reaction rates by enabling the ORR on the entire LSM surface. ${ }^{5}$ In fact, it is the tendency to form particle rafts that can greatly assist in providing stability to the infiltrated cathode performance, so long as the rafts remain in electrical contact. This requirement is much less demanding than maintaining electrical connectivity in spare, single particle networks. Additionally, since the one-step infiltration methods leads mostly to single nanoparticle layers on the pore surfaces, effective electrodes can be obtained at much lower volume fractions than used by other workers. ${ }^{4,6-9}$

Figure 2 reveals a tendency for some orientation alignment of the nanoparticulate LSM particles with the SSZ. The significance of the orientation is so far unknown, but may affect the ORR, particularly at lower temperatures, depending on which surface orientations of the nanoparticulate LSM are presented to the gas phase.

Figure 3 shows that the contact angles of some individual LSM nanoparticles with the surface of the SSZ before and after 502 hrs at temperature have not meaningfully changed. However, in the asformed stage contact between the LSM particles and the SSZ pore walls shows a tendency to be more sporadic than after some time at operating temperatures, Figures 4a and 4b.

The cell voltage of an anode supported SOFC with an LSM infiltrated porous SSZ cathode was recorded at a nearly constant applied current density of $\sim 150 \mathrm{~mA} / \mathrm{cm}^{2}$ for 502 hours at $650{ }^{\circ} \mathrm{C}$, Figure 5. The cell fabricated with a porous SSZ electrode backbone showed no voltage degradation at constant current, and even shows improvement over time. Note that the applied current density was initially set at $150 \mathrm{~mA} / \mathrm{cm}^{2}$, but declined somewhat after 366 hours to a low of $\sim 141 \mathrm{~mA} / \mathrm{cm}^{2}$, due to a 
slight experimental instability; upon readjustment to $150 \mathrm{~mA} / \mathrm{cm}^{2}$ at 457 hours, the cell performance once again returned to the original voltage. These results may be contrasted to those reported by Huang et $a l,{ }^{9}$ which appear to show a significant performance decline after 100 hours at $700^{\circ} \mathrm{C}$.

The improvement of the cell performance is detailed by data shown in Figure 6, which presents the I-V and power curves both before and after the long-term test. The most significant improvement is seen at current densities below $300 \mathrm{~mA} / \mathrm{cm}^{2}$. This region is typically associated with ill-defined activation or reaction losses when using an LSM electrocatalyst. However, the activation is typically complete within a couple of hours in conventional composite LSM-SSZ electrodes, making it unlikely that it is of a similar origin as for the continued increase in performance of the nanoparticulate electrodes over the 502 hour test. Instead, the increase in LSM/SSZ contact, shown in Fig. 4 is viewed as the most likely cause for the gradual improvement.

\section{Conclusion}

A nanoparticulate LSM electrode was produced that was stable for over 500 hours of operation at $650^{\circ} \mathrm{C}$, under a near-constant applied current density of $\sim 150 \mathrm{~mA} / \mathrm{cm}^{2}$. Furthermore, the cell showed some improvement over this period. The stability is attributed in large part to the specific nanoparticle distribution produced by our single-step infiltration method, leading to connected networks and monolayer rafts of nanoparticles that are confined to the pore walls.

The combination of FIB and TEM allowed for an unambiguous imaging of the nanoparticulate infiltrated electrodes, and of the TPB boundaries. Coarsening of the nanoparticles was minimal after more than 500 hours at $650^{\circ} \mathrm{C}$; the tendency for particle raft formation is likely to assist in suppressing coarsening. While contact angles did not appear to change measurably with time, contact between the 
nanoparticulate LSM and the SSZ pore walls tended to increase with time at temperature, as a result of sintering processes, leading to a measurable improvement of the cell performance.

\section{Acknowledgments}

This work was supported by the U.S. Department of Energy through the National Energy Technology Laboratory. The TEM analysis was performed at the National Center for Electron Microscopy at the Lawrence Berkeley National Laboratory. The authors are grateful to Daiichi Kigenso Kagakukogyo for supplying SSZ powder. 


\section{References}

1. K. Yamahara, C. P. Jacobson, S. J. Visco and L. C. De Jonghe, Solid State Ionics, 176 (3-4), 275-279 (2005).

2. C. Lu, T. Z. Sholklapper, C. P. Jacobson, S. J. Visco and L. C. De Jonghe, Journal of the Electrochemical Society, 153 (6), 1115-1119 (2006).

3. M. Watanabe, H. Uchida, M. Shibata, N. Mochizuki and K. Amikura, Journal of the Electrochemical Society, 141 (2), 342-346 (1994).

4. $\quad$ S. P. Jiang, Materials Science and Engineering, A 418 (1-2), 199-210 (2006).

5. T. Z. Sholklapper, C. Lu, C. P. Jacobson, S. J. Visco and L. C. De Jonghe, Electrochemical and Solid-State Letters, 9 (8), 376-378 (2006).

6. Y. Huang, J. M. Vohs and R. J. Gorte, Journal of the Electrochemical Society, 151 (4), 646651 (2004).

7. $\quad$ S. Park, J. M. Vohs and R. J. Gorte, Nature, 404 (6775), 265-267 (2000).

8. Y. Huang, J. M. Vohs and R. J. Gorte, Electrochemical and Solid-State Letters, 9 (5), 237-240 (2006).

9. $\quad$ Y. Huang, J. M. Vohs and R. J. Gorte, Journal of the Electrochemical Society, 152 (7), 13471353 (2005).

10. S. de Souza, S. J. Visco, and L. C. De Jonghe, Journal of the Electrochemical Society, 144 (3), 35-37 (1997).

11. Introduction to Focused Ion Beams, L. A. Giannuzzi and F. A. Stevie, Editors, Springer, New York (2005). 


\section{Figures}

Figure 1. SEM image of FIB cross-sectioned nanoparticulate LSM-infiltrated cathode. The streaking in the image is an unavoidable consequence of the presence of pores. The inset shows the size of some of the LSM nanoparticles.

Figure 2. TEM a) Bright Field, b) Dark Field Patterns and c) corresponding Diffraction Pattern taken on [110] zone axis of SSZ with circle around nanoparticulate LSM reflection used for Dark Field Imaging, showing nanoparticulate LSM grains on the SSZ porous electrode backbone.

Figure 3. TEM Dark Field Images of LSM catalyst particles a) before and b) after 502 hours operation at $650{ }^{\circ} \mathrm{C}$ under $\sim 150 \mathrm{~mA} / \mathrm{cm}^{2}$ applied current. Contact angle changes are not evident.

Figure 4. SEM images of FIB cross-sectioned nanoparticulate LSM infiltrated cathodes a) before and b) after 502 hours operation at $650{ }^{\circ} \mathrm{C}$ under $\sim 150 \mathrm{~mA} / \mathrm{cm}^{2}$ applied current. The contact between the LSM and the SSZ pore walls is more sporadic before testing, as is evident and marked where arrowed in $4 a)$.

Figure 5. Performance of anode supported SOFC with nanoparticulate LSM infiltrated cathode over 502 hours operation at $650^{\circ} \mathrm{C}$ under near-constant applied current of $\sim 150 \mathrm{~mA} / \mathrm{cm}^{2}$.

Figure 6. I-V curve before and after 502 hours operation at $650{ }^{\circ} \mathrm{C}$ under $\sim 150 \mathrm{~mA} / \mathrm{cm}^{2}$ applied current. 
